\title{
TELAAH KITAB AL-SUNNAH QABLA AL-TADWĪN KARYA M. 'AJJAJ AL-KHATIB
}

\author{
Ummi Kalsum Hasibuan, ${ }^{1}$ Sartika Suryadinata ${ }^{2}$ \\ ${ }^{1}$ UIN Sunan Kalijaga Yogyakarta \\ Sleman, Yogyakarta, Indonesia \\ ${ }^{2}$ UIN Sunan Kalijaga Yogyakarta \\ Sleman, Yogyakarta, Indonesia \\ ummi220896@gmail.com
}

\begin{abstract}
Abstrak:
Artikel ini berusaha mengupas tentang kitab al-Sunnah Qabla al-Tadwīn karangan M. 'Ajjaj al-Khatib seorang pemikir Islam yang ahli dalam bidang ilmu hadis berasal dari kota Damaskus. Tujuan tulisan ini adalah untuk menyingkap, menelaah dan mengetahui tentang biografi dari M. Ajjaj alKhatib dan bagaimana sistematika serta selintas lalu tentang pembahasan mengenai isi kitab al-Sunnah Qabla al-Tadwīn lalu terkait dengan bantahan Ajjaj al-Khatib terhadap tuduhan para orientalis tentang sunnah. Kemudian tidak luput dari perhatian mengenai kelebihan dan kekurangan yang ada pada kitab tersebut. Adapun metode yang digunakan dalam artikel adalah metode deskriptif-analisis teks terhadap kitab as-Sunnah Qabla Tadwin dengan menggunakan kitab aslinya.
\end{abstract}

Kata Kunci: Al-Sunnah Qabla Tadwīn, Ilmu Hadis, Orientalis

\begin{abstract}
:
This article explores the book of al-Sunnah Qabla al-Tadwin by M. Ajjaj alKhatib, an Islamic thinker who is an expert in the field of hadith science, coming from the city of Damascus. The purpose of this paper is to uncover, study and find out about the biography of M. Ajjaj al-Khatib and how systematic and fleeting about discussing the contents of the book al-Sunnah Qabla al-Tadwin then related to the rebuttal of Ajjaj al-Khatib sunnah. Then do not need attention about the advantages and disadvantages that exist in the book. The method used in this paper is a descriptive-text analysis method for the book as-Sunnah Qabla Tadwin by using a supported book.
\end{abstract}

Keywords: Al-Sunnah Qabla Tadwīn, Hadith Studies, Orientalis 


\section{Pendahuluan}

Hadis merupakan segala sesuatu yang dihubungkan melalui Rasulullah SAW dari aspek percakapan, perilaku, sifat dan takrir (penetapan). ${ }^{1}$ Hadits juga menjadi penjelas atas al-Qur'an yang maknanya global atau umum. ${ }^{2}$ Selain itu juga merupakan sumber atau pedoman kedua setelah Alquran bagi umat Islam. Pada masa Rasulullah SAW hadis belum dibukukan dan ditulis secara resmi. Sebab pada waktu itu hadis masih diajarkan dan diriwayatkan secara oral dan bacaan. Meskipun hal demikian menutup kemungkinan adanya beberapa sahabat yang menuliskan hadis untuk kebutuhan pribadi.

Seiring berjalannya waktu, perkembangan hadis terus berlanjut dari masa ke masa. Yang mana proses pembukuan hadis tersebut dipelopori oleh khalifah Umar bin Abdul Aziz yang kemudian menjadikannya nilai sejarah yang amat penting. Karena pembukuan hadis itu menjadi bukti keberhasilan dalam sejarah perkembangan hadis yang sebelumnya, hadis hanya dijaga dalam bentuk hafalan kemudian dibukukan ke dalam kitab-kitab hadis. ${ }^{3}$

Dalam pembahasan kitab ini Ajjaj al-Khatib telah membuktikan bahwa selama periode-periode hadis belum terkodifikasi, hadis tersebut tetap terjaga dengan baik melalui tulisan dan hafalan para sahabat melalui bukti-bukti adanya tulisan dan dokumen mengenai hadis. ${ }^{4}$ Meskipun ketika dalam perjalanannya telah terjadi manipulasi terhadap hadis yang dilaksanakan oleh sekelompok orang dari kalangan tertentu.

Dalam hal ini, peneliti sangat tertarik untuk mengkaji lebih jauh lagi terhadap kitab al-Sunnah Qabla Tadwin. Sehingga kajian kitab ini bermula pada biografi dari penuis kitab, selanjutnya terkait dengan kitab tersebut. baik dari aspek latar belakang penulisan kitab, sistematika kitab, kelebihan dan kekurangan kitab.

\section{Sekilas Biografi Kehidupan M. Ajjaj al-Khatib}

Ajjaj al-Khatib merupakan seorang tokoh pemikir Islam terkenal khususnya dalam bidang ilmu hadis, yang memiliki namaasli Dr. M. Ajjaj bin Muhammad Tamim bin Salih bin Abdullah al-Hasani al-Hasyimi al-Khatib lahir di Damaskus, Syiria pada tahun 1350 H/ 1932 M.Ketika muda ia dikenal sebagai seorang yang pintar. Ajjaj al-Khatib menempuh pendidikannya di kota Damaskus, selain belajar di sekolah beliau juga sering mengikuti berbagai halaqah-halaqah keilmuan di masjid Bani Umayyah. Kemudian beliau

${ }^{1}$ Riza Nazlianto, "Hadits Zaman Rasulullah SAW dan Tatacara Periwayatannya oleh Sahabar," Al-Murshalah 2, no. 2 (2018): 44.

${ }^{2}$ Rasyad, "Tinjauan Kitab Syarah Sunan Abi Dawud 'Bazdl al-Majhud Fi Halli Aby Dawud'," Al-Mu'ashirah 15, no. 2 (2018): 143.

${ }^{3}$ Edi Safri, Metode Takhrij al-Hadis (Padang: Hayfa Press, 2014), 1.

${ }^{4}$ M. 'Ajjaj al-Khatib, Hadis Nabi Sebelum Dibukukan, terj. AH. Akrom Fahmi (Jakarta: Gema Insani Press, 1999), 2. 
melanjutkan jenjang pendidikannya di sekolah guru Dar al-Mu'allimin alIbtidaiyyah lulus pada tahun 1951/1952 M dan mengikuti praktek mengajar.

M. Ajjaj al-Khatib pernah mengajar di salah satu sekolah menengah kota Damaskus sekitar tahun 1952-1959 M. Selain mengajar beliau juga melanjutkan sekolahnya di Fakultas Syari'ah Universitas Damaskus tahun 1958/1959 M dan mendapatkan gelar sarjananya. Ia mendapatkan beasiswa program Magister di Universitas Kairo dan lulus pada tahun 1962 kemudian meraih gelar P. h. D di Universitas yang sama pada tahun 1965 dengan konsentrasi ilmu hadis. Pada tahun 1966-1969 M. Ajjaj al-Khatib diberi amanah untuk menjadi dosen pada jurusan ilmu al-Qur'an dan sunnah Fakultas Syari'ah Universitas Damaskus.

Dalam belajar Ajjaj al-Khatib banyak menimba ilmu kepada ulama-ulama, di antaranyaSyaikh Hashim al-Khatib, Syaikh Dr. Muhammad Amin al-Misri, Syaikh 'Abd al-Wahhab al-Hafiz, Syaikh Sa'id al-Burhani, Prof. Dr. Mustafa alZarqa, Prof. Dr. Mustafa al-Siba'i, Prof. Mustafa Khan dan lain-lain.

Dalam hal ini, selain kitab al-Sunnah Qabla al-Tadwin, Ajjaj al-Khatib memiliki beberapa karya yang lainnya, di antara karyanya adalah sebagai berikut:

1. Kitab tentang Zaid bin Tsabit (1959 M)

2. Kitab Abu Hurairah Riwayah al-Islam(1963 M)

3. Kitab Ushul Hadits 'Ulumuh wa Mustalahuh(1968 M merupakan cetakan pertama dan cetakan kedua pada tahun $1997 \mathrm{M}$ )

4. Kitab Qabasat min Hadits al-Nabawiyah (1967 M)

5. Kitab Lamahat fi al-Makhtabah al-Bahtsa al-Mashadir (1969 M)

6. Kitab al-Wafiz fi ulum al-Hadits wa Nususih

7. Kitab al-Sunnah Hujjiyatuha wa Ma'natuha min al-Tashri' wa alQur'an al-Karim wa Daf'u Ba'd al-Subhat 'anha (2009) ${ }^{5}$

\section{Kitab al-Sunnah Qabla al-Tadwīn}

Kitab al-Sunnah Qabla al-Tadwīn merupakan tesis dari Dr. M. Ajjaj alKhatib yang diterbitkan oleh Maktabah Wahabah, Kairo pada tahun 1963 M terdiri 656 halaman dan terdapat satu jilid. ${ }^{6}$ Kajian kitab ini berfokus pada periode sebelum pembukuan, yakni periode al-Wahyu wa Takwin, periode Iqbal al-Riwayah dan periode Intisyar al-Riwayah. Ajjaj al-Khatib memiliki ketertarikan sendiri terhadap judul kitab ini karena belum adanya ulama yang membahas hal ini secara mendalam maupun terperinci. Kalaupun ada, itu hanyalah sepintas lalu saja dalam membahasnya. ${ }^{7}$ Serta kitab ini juga merespon

5 Andri Putra, "Konsep 'Adalah dan Dhabth Menurut Muhammad Ajjaj alKhatib dan Ja'far Subhani Studi Komparatif KItab Ushul Hadis dan Ushul Hadis wa Ahkamuhu" (UIN Sultan Syarif Kasim Riau Fakultas Ushuluddin, 2013), 27.

${ }^{6}$ M. 'Ajjaj al-Khatib, Al-Sunnah Qabla al-Tadwinn (Kairo: Maktabah Wahabah, 1963).

${ }^{7}$ M. 'Ajjaj al-Khatib, Al-Sunnah Qabla al-Tadwīn, 24. 
masuknya pemikiran-pemikiran Prancis yang dibawa oleh mahasiswa Mesir yang melanjutkan studinya di Prancis.

Menurut Ajjaj al-Khatib pembukan sunnah secara resmi di mulai pada pertengahan abad kedua hijriah yang di pelopori oleh Abdul Aziz bin Marwan ibn al-Hakam selaku gubernur Mesir. Beliau meminta Katsir bin Murrah alHadrami untuk menuliskan hadis yang didengarnya dari para sahabat. Kemudian pembukuan hadis secara resmi ini dilanjutkan oleh anaknya, yaitu Umar bin Abdul Aziz, lalu meminta kepada para ulama di berbagai wilayah kekuasaan Islam untuk menuliskan dan mengkaji hadis secara bersama-sama. ${ }^{8}$

Dalam kitab ini Ajjaj al-Khatib juga mengkaji mengenai pemalsuan sunnah dan sebab-sebabnya serta usaha para sahabat dan generasi selanjutnya untuk mengatasi dampak-dampak dari pemalsuan sunnah. Selain itu beliau juga mengemukakan pendapat sebagian orientalis yang telah berhasil menipu kaum muslimin dengan pendapat mereka. Sehingga dalam pembahasan ini beliau membantah pendapat serta tuduhan para orientalis tersebut dan meluruskannya.

Adapun pendapat salah satu orientalis, yakni Goldziher dalam bukanya Dirasat Islamiyah menyatakan bahwa, "hadis adalah suatu hasil dari pertumbuhan Islam dari aspek politik dan sosial”. Dalam hal ini 'Ajjaj al-Khatib membantah tuduhan Goldziher, yang mana menurutnya pendapat itu tidak benar, karena sejak abad pertama dan masa sahabat umat Islam telah melakukan pembuktian terhadap hadis-hadis dan memberantas para pemalsu hadis. Sehingga mereka mengetahui mana hadis yang palsu dan Shahih. ${ }^{9}$

Gostown Wite menguatkan pendapat Goldziher. Ia berpendapat, "para ulama telah mengkaji sunnah secara cermat. Kajian mereka itu diarahkan kepada sanad hadis, tentang para perawi hadis, pertemuan di antara mereka, dan aktivitas mendengar sebagian dari mereka dari sebagian yang lain." Kemudian ia berpendapat lebih lanjut bahwa "para perawi menukil hadis Rasulullah kepada kita secara verbal, lalu dihimpun dan dibukukan oleh para penghafal hadis. Namun mereka tidak melakukan terhadap kritik matan suatu hadis. Oleh karena itu, kami tidak yakin jikalau hadis itu sampai kepada kita persis seperti yang disampaikan oleh Rasulullah SAW tanpa adanya penambahan oleh perawi. Mereka bisa saja melakukan penambahan pada periwayatannya karena hadis dinukil secara verbal." Mengenai bantahan "Ajjaj al-Khatib terhadap tuduhan di atas, ia menolak setiap tuduhan yang berbicara tentang kritik para jumhur ulama terfokus pada suatu rujukan hadis semata dan mengabaikan matan hadisnya. Ajjaj al-Khatib menegaskan bahwa para ulama telah menentukan ciri-ciri dalam

\footnotetext{
${ }^{8}$ M. 'Ajjaj al-Khatib, Al-Sunnah Qabla al-Tadwīn.

${ }^{9}$ M.'Ajjaj al-Khatib, Hadis Nabi Sebelum Dibukukan, terj. AH. Akrom Fahmi, 301303.
} 
membedakan antara sanad yang lemah dan shahih, dan juga telah menentukan ciri-ciri untuk membedakan hadis palsu dengan hadis lainnya. ${ }^{10}$

Menjawab tuduhan Gostown Wite, bahwa perawi telah manambahkan sesuatu pada hadis yang mereka riwayatkan juga tertolak.Penambahan sesuatu oleh perawi pada hadis yang diriwayatkannya itu ada, yang disebut al-mudraj, yang mana hanya terdapat pada matan saja.Sebagian besar penambahan oleh perawi itu bersumber dari penjelasan guru yang mereka dengar dan mengira penjelasan itu termasuk dalam bagian hadis.ulama menjelaskan penambahanpenambahan itu merupakan kesalahan yang tidak disengaja dan mereka tidak berdosa. Hanya saja jika kesalahannya banyak maka dapat menimbulkan kecacatan terhadap perawi. ${ }^{11}$

\section{Sistematika Bahasan Kitab}

Kitab al-Sunnah Qabla al-Tadwīn ini secara umum tersusun sistematis yang terdiri atas bagian pengantar, lima bab pembahasan, dan bagian penutup, dengan susunan pembahasan sebagai berikut:

\section{PENGANTAR}

a. Pengertian al-Sunnah menurut bahasa dan Syara'

$b$. Objek al-Sunnah dan kedudukannya terhadap Alquran

\section{BAB I: Al-Sunnah Pada Masa Nabi SAW}

Pada bab 1 membahas terkait Rasulullah SAW menjadi guru dan pengasuh serta perilkau Rasulullah SAW terhadap ilmu metode dakwahnya, pengasuhannya pada sahabat dan signifikansi para sahabat terkait dengan alSunnah. Kemudian pembahasan ditutup dengan sub kajian tentang tersebarnya al-Sunnah ketika zaman Rasulullah SAW.

\section{BAB II: Al-Sunnah ketika Zaman Sahabat Dan Tabi'in}

Pembahasan bab kedua di bagi kepada dua ihwal. ihwal pertama meliputi beberapa bahasan, yakni:

a. Peneladanan sahabat dan tabi'in kepada Rasulullah SAW dan ketegaran mereka berpegang pada hadis.

$b$. Kewaspadaan dan perilaku wara' sahabat dan tabi'in dalam menyampaikan hadis

c. Validasi sahabat dan tabi' in ketika menerima hadis

d. Periwayatan hadis ketika zamannya: melalui bil lafzhi atau bil ma'na Ihwal kedua terdpat tiga sub bahasan, yaitu:

a. Kegiatan ilmiah zaman sahabat dan tabi'in

$b$. merebaknya hadis zaman sahabat dan tabi'in

c. penjelajahan dalam melacak hadis

${ }^{10}$ M. 'Ajjaj al-Khatib, Hadis Nabi Sebelum Dibukukan, terj. AH. Akrom Fahmi, 304-305.

${ }^{11}$ M. 'Ajjaj al-Khatib, Hadis Nabi Sebelum Dibukukan, terj. AH. Akrom Fahmi, 307. 


\section{BAB III: Pemalsuan Hadis}

Bab ketiga terdapat empat ihwal, adalah:

a. Ihwal 1: awal mula terjadinya manipulasi hadis dan penyebabnya

b. Ihwal 2: cara para sahabat dan tabi'in dan orang-orang yang mengikuti mereka dalam menghadapi manipulasi hadis dan cara memelihara hadis

c. Ihwal 3: pandangan orientalis dan pendukung-pendukung mereka mengenai al-Sunnah dan kritik mereka terhadap al-Sunnah

d. Ihwal 4: Kitab-kitab terpopuler tentang rijalul hadis dan hadis-hadis maudhu' penyusunan kitab oleh jumhur ulama dari hasil kesusahan mereka dalam memelihara hadis.

\section{BAB IV: Kapan Hadis Dibukukan}

Pada bab empat terdiri dari tiga perkara:

a. Perkara satu: seputar pendataan hadis. disini disebutkan hadis-hadis yang disepakati penyususnannya al-Sunnah dan hadis-hadis yang tidak sepakat dalam penyusunannya.

b. Perkara dua: Apakah yang telah dicatat ketika zaman Rasulullah SAW dan awal mulanya Islam?

c. Perkara tiga: seputar pendapat tentang penyusunan atau penulisan Hadis

6. BAB V: Pembahasan tentang Periwayat Hadis Kalangan Sahabat Dan Tabi'in

Bab ini terdiri dari dua pasal, yaitu adalah sebagai berikut:

a. Bahasan Pertama: tokoh periwayat hadis dari kalangan sahabat, dalam hal ini mengkaji terkait dengan defenisi sahabat, keadilan sahabat dan biografi para sahabat yang jumlahnya banyak dalam menyampaikan hadis, adalah Abū Hurairah, Abdullah ibn 'Umar, Anas ibn Malik, 'Aisyah Ummul Mu'minin, Abdullah bin Abbas, Jabir bin Abdullah dan Abū Sa'̄̄d al-Khūdri.

b. Bahasan Kedua: periwayat hadis dari kalangan tabi'in, yaitu Sā'id ibn Musayyab, Urwah ibn Zubair, Muhammad ibn Muslim bin Shihab al-Zuhri, Nafi', Ubaidillah ibn 'Abdullah, Salim ibn Abdullah ibn 'Umar, Ibrahim an-Nakha'i, Amir asy-Sya'bi, Alqamah anNakha'i, Muhammad ibn Sirin. ${ }^{12}$

\section{Kelebihan Dan Kekurangan}

Kitab al-Sunnah Qabla al-Tadwīn memiliki kelebihan dan kekurangan yang terdapat di dalamnya, adapun kelebihannya adalah:

1) Secara umum kitab ini sangat menarik dan bagus, karena dalam kitab ini memberikan banyak informasi tambahan dalam melakukan

\footnotetext{
${ }^{12}$ M. 'Ajjaj al-Khatib, Al-Sunnah Qabla al-Tadwīn, 4-7.
} 
pengkajian terhadap hadis serta kita bisa mengetahui tentang sejarah perjalanan hadis sebelum dibukukan tersebut.

2) Kitab ini tersusun secara sistematis dan membaginya menjadi lima bab.

3) Kitab ini merupakan tesis Ajjaj al-Khatib, oleh karena itu beliau sangat bekerja keras mencari rujukan untuk penyusunan kitab ini.

4) Dalam kitab ini terdapat bantahan Ajjaj al-Khatib terhadap orientalis, selain itu juga terdapat pembahasan khusus tentang pemalsuan hadis

Sedangkan kekurangan dari kitab ini, yaitu:

1) Pembahasan dalam kitab ini hanya terfokus pada proses sunah sebelum dibukukan.

\section{Kesimpulan}

M. 'Ajjaj al-Khatib merupakan sosok yang ahli dalam kajian ilmu hadis berasal dari Damaskus yang dilahirkan tahun 1350 H/ 1932 M. Kitab al-Sunnah Qabla al-Tadwin ini merupakan tesis dari Dr. M. Ajjaj al-Khatib yang mana ketika menjelaskan tentang proses hadis sebelum dibukukan itu dengan sangat detail dan akurat. Sistematika penulisan kitab ini tersusun sistematis yang pembahasannya terdiri lima bab dan terdapat sub-sub bahasan di dalamnya.

\section{Daftar Pustaka}

Andri Putra. "Konsep 'Adalah dan Dhabth Menurut Muhammad Ajjaj al Khatib dan Ja'far Subhani Studi Komparatif KItab Ushul Hadis dan Ushul Hadis wa Ahkamuhu" (UIN Suska Riau Fakultas Ushuluddin, 2013).

Al-Khatib, M. Ajjaj. Hadis Nabi Sebelum Dibukukan, terj. AH. Akrom Fahmi. Jakarta: Gema Insani Press, 1999.

Al-Khatib, M. Ajjaj. Al-Sunnah Qabla al-Tadwinn. Kairo: Maktabah Wahabah, 1963.

Nazlianto, Riza. "Hadits Zaman Rasulullah SAW dan Tatacara Periwayatannya oleh Sahabar." Al-Murshalah 2, no. 2 (2018).

Rasyad. "Tinjauan Kitab Syarah Sunan Abi Dawud 'Bazdl al-Majhud Fi Halli Aby Dawud'." Al-Mu'ashirah 15, no. 2 (2018).

Safri, Edi. Metode Takhrij al-Hadis. Padang: Hayfa Press, 2014. 